\title{
Los niños, victimas del abuso sexual intrafamiliar.
}

Josefa Hernández Hernández ${ }^{1}$
Asesor: M.P.P. Arturo Monroy Gutiérrez

\section{Resumen}

En el siguiente escrito se analiza el problema que se presenta en el núcleo familiar: los niños víctimas del abuso sexual intrafamiliar; los pequeños son integrantes indefensos y en varias ocasiones se les priva de sus derechos y de su bienestar dentro del sistema familiar. Se muestra que a lo largo de la historia el problema del abuso sexual en los menores se ha incrementado; a lo largo del trabajo se muestran las consecuencias psicológicas en las víctimas y las repercusiones que éstas contraen en las diferentes etapas de su vida.

\section{Abstract}

In the following written discusses the problem that occurs in the family: children as they are the main victims in sexual abuse within the family, being defenseless members, depriving them of their rights and welf are within the family system. This also shows that through out history the problem of sexual abuse on children has been increasing, the main factors of the victims, the psychological consequences and repercussions that this contract at different stages of life of the infant.

\section{Introducción}

La familia sigue siendo el núcleo más importante dentro de la estructura social; en ella la mayoría de los seres humanos se han criado; existen casos en los que la familia contribuye al bienestar de los infantes, pero también hay ocasiones en las que ésta empaña u obstaculiza el crecimiento de los pequeños.

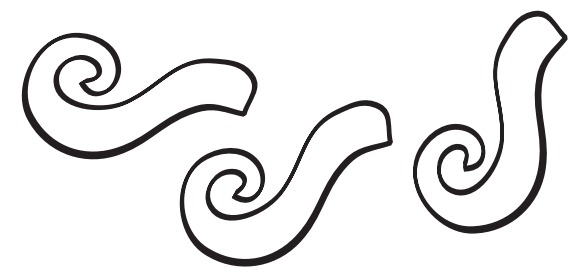

Mediante el siguiente escrito se intenta abarcar el crucial problema que hoy en día se presenta en algunos menores de edad dentro del núcleo familiar: el abuso sexual, las consecuencias que éste trae al infante en su trayecto de vida individual, psicológica, social y familiar. La violencia intrafamiliar ha tenido gran impacto y las fuentes que generan esta situación son diversas: la ignorancia de los padres, porque los progenitores no saben controlar sus impulsos, existe falta de comprensión entre las parejas; y sobre todo la violencia se genera porque los padres no saben ser tolerantes.

Los padres, hijos, hermanos, primos, tíos, todos los que conforman el sistema familiar cierran sus ojos inconscientemente ante el abuso sexual que pueden estar padeciendo los pequeños, los padres puede olvidarse de su rol de protectores del sistema familiar.

\section{Problema de investigación}

Los niños que han sido abusados sexualmente dentro del núcleo familiar tienen problemas a lo largo de trayecto de vida.

\section{Preguntas de investigación}

- ¿Cuáles son los factores que propician que el abuso sexual a menores se mantenga en secreto dentro de la familia?

- ¿Qué situaciones influyen para que en algunas familias haya interacciones disfuncionales entre sus miembros? 


\section{Objetivo general}

Identificar las consecuencias psicológicas y los problemas de socialización que acarrea al abuso sexual de infantes en el seno familiar (Caso de una niña de 15 años).

\section{Objetivo particular}

- Describir las principales consecuencias que ocasiona en la vida del infante el abuso sexual que se da al interior del seno familiar.

- Promover en el lector la concientización respecto a las consecuencias negativas que acarrea el abuso sexual a niños dentro de la familia.

\section{Justificación}

Los infantes desconocen cómo se relacionan sus padres como pareja. Desafortunadamente los niños que son víctimas de abuso sexual al interior de sus familias desconocen si lo que han padecido está bien o mal. Es en el núcleo familiar donde se aprenden valores y principios; en las casas donde se generan abusos sexuales hacia menores se propicia la formación de personas con problemas de socialización, por ende, se tiene muchas posibilidades de estar formando a futuros delincuentes, secuestradores, violadores, gente con desviaciones sexuales, etc.

\section{Marco teórico}

El abuso sexual se ejerce al forzar a la persona a través de las amenazas. En el abuso sexual la persona agresora hace gala de sus pulsiones $y$ tiene dificultades para regular y controlar sus impulsos. En el caso de este trabajo el agresor so alcanzó a incorporar a su mente que su hija tiene una relación significativa y consanguínea con é. La prohibición no fue incorporada en las funciones mentales del padre.
Gracias a la aportación de la psicóloga de la institución del asilo para personas y familias maltratadas, pude rescatar la siguiente información sobre el caso de Lucrecia, una adolescente de 15 años cuyo padre de 48 siempre ha maltratado a su pareja y ha forzado a su hija al abuso sexual desde hace siete años.

Esta familia vive en un pueblo marginado, donde el machismo y el alcoholismo son características comunes entre los hombres que ahí viven. La madre de Lucrecia tiene 40 años y 3 hermanas menores que ella; la mamá mencionó que no sabía nada respecto a los abusos del padre hacia Lucrecia. Desafortunadamente la mamá fue cómplice inconsciente al permitir el abuso del padre a la hija. Ella se reprochaba no haber sido virgen al momento de casarse (había tenido dos hijos con anterioridad). Los abusos del padre hacia Lucrecia excedieron límites y se empezaron a dar enfrente de varias personas. Todo inició con mentiras del padre hacia la jovencita respecto a la historia de Adán y Eva. El señor vivía dos realidades al mismo tiempo: mantenía muy ocupada a su esposa con los quehaceres del hogar y por otro lado, se daba tiempo para pasear con Lucrecia con la intención de ganar su confianza y posteriormente abusar de ella.

Años más tarde a los abusos del padre, la madre y sus hijas acudieron a una cita médica y Lucrecia, por primera vez, pudo hablar con una psicóloga respecto a lo que estaba padeciendo. La niña creía que lo que estaba haciendo con su padre era correcto y normal. La psicóloga le explicó que eso era maltrato y abuso sexual hacia ella y hacia su familia, entonces la profesional habló con la madre de Lucrecia para explicarle lo que estaba sucediendo con su hija. La negación de la madre fue evidente, pero afortunadamente tomó una decisión acertada y decidió aceptar ayuda profesional para ayudar a Lucrecia y evitar que sus otras hijas también se convirtieran en víctimas. 


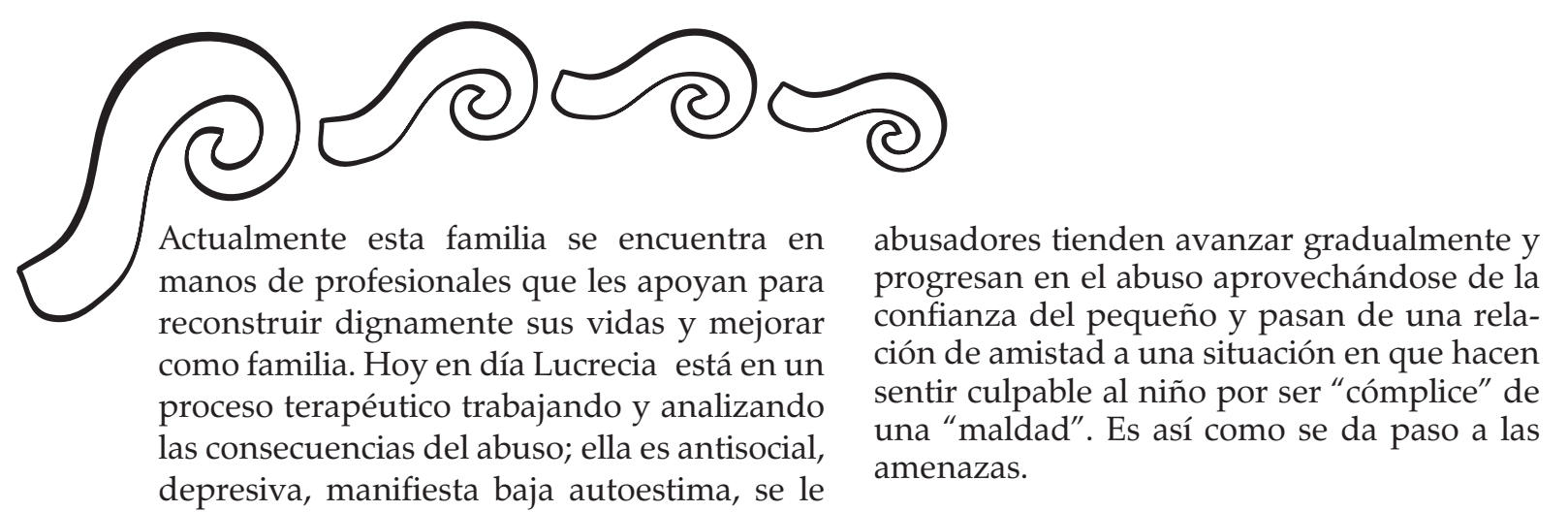
dificulta expresar su sentimientos y no le gusta relacionarse con niños y adolescentes de su edad, dice que los hombres son malos, que solo hacen sufrir y es por ello que se aleja de ellos lo más posible. No tiene amigos en la escuela, solo cuenta con una o dos compañeras de salón, esto es un grave problema ya que puede manifestar fobias y alteraciones sexuales, pues las personas que pasan por este trance se sienten amenazadas constantemente y tienen insuficiencia de identidad.

Según Madanes (1993), la mayoría de los problemas que precisan terapia derivan de la oposición entre el amor y la violencia. La cuestión principal entre los seres humanos es la de si deben amarse, protegerse y ayudarse entre sí, o entrometerse, dominar y controlar, haciendo daño y ejerciendo la violencia sobre los demás.

Según Canavan y Meyer, (1992) Se calcula que el $65 \%$ de las mujeres fueron víctimas alguna vez, durante la infancia de un acto de abuso sexual incestuoso. El incesto padre-hija es el más frecuente de acuerdo a una muestra de 95 casos de relación incestuosa realizada en los Estados Unidos, 42 casos tuvieron lugar entre padre e hija, 26 entre hermanos, 17 entre abuelo y nieta y 10 entre primos y otros parientes. En México es difícil establecer una estadística ya que no se reporta la mayoría de los casos.

El abuso intrafamiliar es cometido por personas cercanas a la familia como: padrastros, padres biológicos, hermanos, tíos, primos o parientes muy cercanos. Estos abusadores compensan sus problemas de pareja a través de la relación sexual con los niños. Como pertenecen a la familia y están en estrecho contacto con los pequeños, el abuso es sostenido en el tiempo y se da de manera progresiva. Estos

Detrás de un abusador existen muchos factores a considerar como son: una historia familiar en la cual se ha sufrido abuso cuando era niño, problemas actuales a nivel de la relación sexual con la pareja o historia personal de algún tipo de maltrato.

\section{Caracterización del abusador:}

a) Abusadores que buscan una relación sexual con un niño para compensar su mala relación con su pareja, tienden a abusar de los niños de su propia familia: hermanos, padres o parientes muy cercanos.

b) Los abusadores que no lograron tener un desarrollo normal de su sexualidad (se quedan estancados en la niñez) y no son capaces de establecer una relación sexual adulta normal con una pareja.

c) El acosador busca establecer una confianza y dependencia entre el niño, cuando lo logra comienza con actos de exhibición y al final hay tocamientos.

\section{Secreto familiar:}

El incesto no solo es vivido e involucra a los niños y al abusador sino que se involucra al resto de la familia. El mantener en secreto los abusos permite "equilibrar" los problemas de pareja, sin embargo, el más afectado será el niño quien sufrirá severos daños en su desarrollo.

Las madres de familias cuyos hijos sufren abuso sexual, generalmente provienen de casas en las que ellas también padecieron abusos por parte de un adulto. 


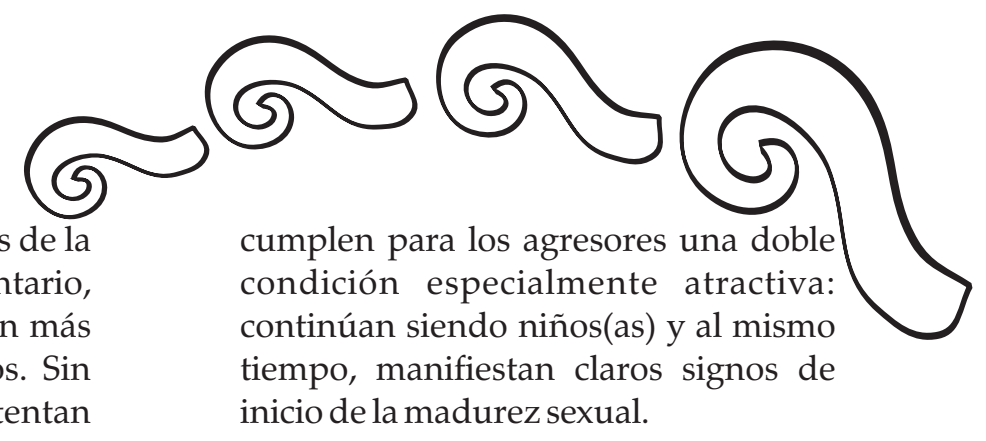

Monroy (1994), nos habla en sus escritos de la dualidad del incesto: acto complementario, en que las mujeres de estas familias son más esposas que madres, frente a sus hijos. Sin embargo, las relaciones de pareja que intentan cuidar no las hacen felices ya que están constantemente dejándose llevar por las demandas del marido o pareja y están constantemente en conflicto con él. Ninguna de estas alternativas los hace sentirse queridos y comprendidos por el otro y el primer aspecto que se ve afectado es la vida sexual. Esta mala relación a nivel sexual es la que los abusadores intentan compensar con las hijas.

Es esencial conocer cuáles son los factores de riesgo y protección, dado que nos ayudarán a definir los enfoques de los programas preventivos y evitar que muchos niños (as) se conviertan en víctimas.

Según el informe elaborado por Save the children (1998), los abusos sexuales pueden afectar a niños (as) de cualquier edad y situación social; aún así, los estudios realizados señalan ciertos factores que permiten aproximar algunas de las características parte de las víctimas:

- Las niñas son más víctimas que los niños. Los resultados de los estudios coinciden en que las mujeres sufren el abuso sexual infantil tres veces más que los hombres.

- Las condiciones que favorecen el empleo de la violencia con los niños están asociadas a un mayor riesgo de sufrir abusos sexuales: pobreza, bajo nivel cultural, viviendas inadecuadas, abuso del alcohol.

- La edad comprendida entre los 10 y los 15 años es la de más riesgo. Es la etapa de los cambios asociados con la pubertad, que aumentan la vulnerabilidad de los niños.

- Los preadolescentes, entre 12 y 14 años,

\section{Consecuencias del abuso sexual}

Los abusos sexuales tienen efectos perjudiciales para el desarrollo psicoemocional, sexual y social del niño(a), ya que ponen en peligro la imagen que el niño tiene de sí mismo. Un niño que es abusado siente que su cuerpo ha sufrido daños que no tienen arreglo ya que sienten que nunca más volverán a ser personas normales.

Se caracterizan por tener un enorme miedo a volver a ser agredidos, vivir nuevamente los mismos actos y viven aterrorizados frente a las amenazas de daño de parte del abusador, tienen insomnio o pesadillas, viven angustiados. En este sentido, todo puede resultar un recordatorio de su problema: una película, el que algún niño de su edad les declare su amor, o tienen miedo a quedarse solos.

En el caso de Lucrecia ella presenta síntomas de angustia y está constantemente triste, sucia, despreocupada con su apariencia. Las personas que han pasado por este suceso se deprimen y esto se manifiesta en falta de ánimo, enfermedades, la angustia y desesperación pueden llevarlos al suicidio, esto es una forma de pedir ayuda ya que no saben qué hacer con su vida. Todo lo que sienten de sí mismos es culpa y vergüenza.

El papel de la familia es esencial en la recuperación física y emocional del niño (a) que ha sufrido de abuso sexual. La atención que se le ha de proporcionar a este infante no debe centrarse únicamente en el cuidado de sus lesiones físicas, sino debe ser coordinada entre distintos profesionales, se le debe prestar atención psicológica.

Es importante recordar que algunos niños 


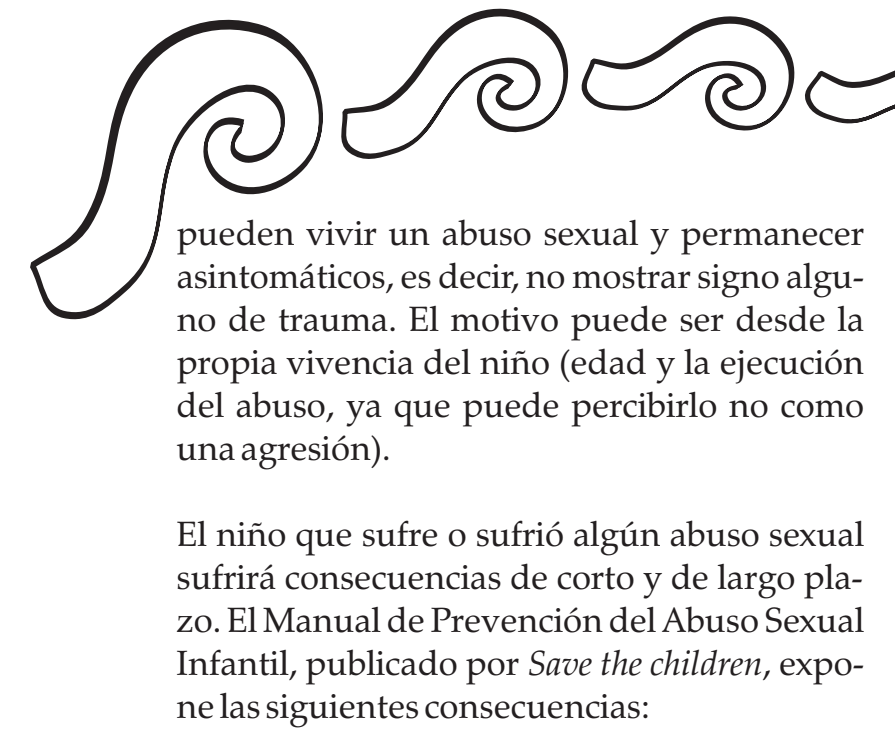

\section{Consecuencias a corto plazo del abuso sexual infantil}

- Físicas: pesadillas y problemas de sueño, pérdida de control de esfínteres.

- Conductuales: consumo de drogas y alcohol, fugas, conductas auto lesivas o suicidas, hiperactividad, baja del rendimiento académico.

- Emocionales: miedo generalizado, agresividad, culpa y vergüenza, aislamiento, ansiedad, depresión, baja estima, rechazo al propio cuerpo.

- Sexuales: conocimiento sexual precoz e impropio a su edad, masturbación compulsiva, exhibicionismo, problemas de identidad sexual.

- Sociales: déficit en habilidades sociales, retraimiento social, conductas antisociales.

\section{Consecuencias a largo plazo del abuso sexual infantil}

Existen consecuencias de la vivencia que permanecen o, incluso, pueden agudizarse con el tiempo, hasta llegar a configurar patologías definidas.

- Físicas: dolores crónicos generales, hipocondría o trastornos psicosomáticos, alteraciones del sueño y pesadillas constantes, problemas gastrointestinales, desorden alimentario.

- Conductuales: intento de suicidio, consumo de drogas y alcohol, trastorno de identidad.

- Emocionales: depresión, ansiedad, baja estima, dificultad para expresar sentimientos.

- Sexuales: fobias sexuales, disfunciones sexuales, falta de satisfacción o incapacidad para el orgasmo, alteraciones de la motivación sexual, mayor probabilidad de sufrir violaciones y de entrar en la prostitución, dificultad para establecer relaciones sexuales.

- Sociales: problemas de relación interpersonal, aislamiento, dificultades de vinculación afectiva con los hijos.

\section{Cómo se trata el abuso sexual}

El abuso sexual debe ser enfrentado con apoyo profesional psicológico, familiar y sobre todo el afectado debe querer ser ayudado, rompiendo el silencio que guarda debido a la culpa y angustia que ha experimemtado.

Recibir terapia psicología para reivindicar su integridad, confianza y autoestima. Debe asistir a terapia de grupo en la que aprenderá que no es la única persona que se encuentra en tal situación.

Hacer una denuncia de abuso sexual requiere de mucha fuerza y valentía ya que se debe recordar el o los episodios de abuso y someterse a exámenes médicos y ginecológicos, además de una terapia familiar e individual que permitan hacer una denuncia fundamentada en pruebas concretas de que el abuso existió. 


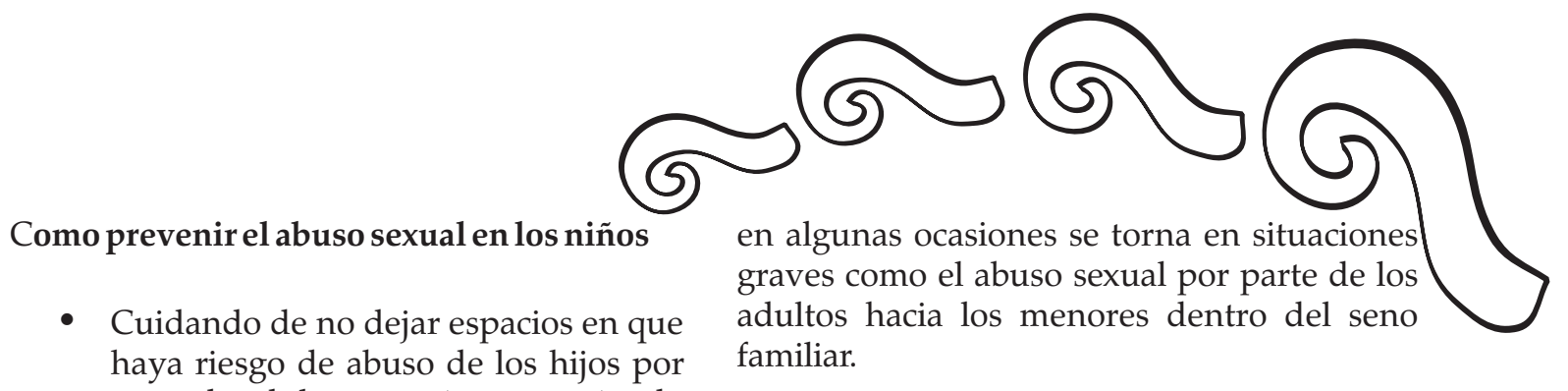
parte de adultos extraños y enseñando a los niños a no aceptar caricias de desconocidos y familiares que vayan al toque intimo.

- Los padres deben transmitir confianza a los hijos, para que ellos puedan hablar de lo que sienten y les pasa.

- Enseñarle al niño del valor que tiene su cuerpo y el deber que tiene de cuidarlo ya que nadie tiene derecho irrumpir su privacidad.

- El abuso por parte de los padres es más difícil de prevenir ya que las familias tienden a no pedir ayuda cuando viven problemas a nivel de la pareja y especialmente sexual. Pero la clave está en ser capaces de conversar y explicarle al niño con toda claridad las conductas propias de un abuso y qué hacer cuando alguien los toque de manera distinta a la permisible.

\section{Metodología}

\section{Enfoque de investigación}

La investigación se realizó mediante el apoyo que tuve de una psicóloga, ya que no tuve el placer de interactuar de manera directa con el paciente.

\section{Alcances}

Se plasmaron en este documento, mismo que se reorganizó mediante el apoyo de varios autores.

\section{Hipótesis}

Las relaciones disfuncionales entre las parejas originan un uso inadecuado en la transmisión de valores y principios hacia los hijos, lo que

\section{Resultados}

Los resultados que se obtuvieron mediante esta análisis del problema en el sistema familiar es muy amplio, ya que en los integrantes de la familia carecen de comunicación, no existen confianza para transmitir aquellas inquietudes que presentan los miembros y prefieren seguir guardando silencio, esperando que el otro sea quien rectifique por sí mismo, el guardar silencio obedece a algo cultural, pues la solución de problemas a través de diálogos no es algo que se dé con frecuencia.

El infante manifiesta sus dolencias en silencio, que es provocado mediante amenazas de los adultos que han abusado de ellos.

\section{Conclusiones}

El abuso sexual que ejercen algunos adultos hacia infantes de su propia familia existe, se trata de un conflicto edípico que traspasó las líneas de lo imaginario y fantástico y se plantó en el mundo real. Las hijas pueden expresar un amor edípico hacia su padre, pero de forma inconscientemente, situación que puede provocar una alteración emocional que les impide a las niñas enfrentar la realidad y poner límites a los abusos que ha recibido.

Se pudieron dar a conocer los rasgos principales del abuso hacia menores y las consecuencias a corto y largo plazo que éste trae a la vida del niño en el transcurso de su vida.

Se narró el caso de una niña de 15 años que ha padecido el abuso de su padre, se eligió la historia anterior para ofrecerle al lector información verídica respecto a una situación que desafortunadamente se da en familias de distintos niveles socioculturales. Debe dejarse claro que el apoyo psicológico profesional es imprescindible para ayudar a los infantes y a las familias que han sufrido esta situación. 


\section{Fuentes de consulta:}

SANZ, D., y Molina A. (1999). Violencia y abuso sexual en la familia. Editorial Lumen.

MARTÍNEZ, T. A. (1900-2001).Prevención de la violencia intrafamiliar. México D.F. Editorial Porrúa.

MADANES, C. (1993). Sexo, amor y violencia: estrategias de transformación. Editorial Paidós Ibérica, S. A.

MINUCHIN, S. Y Fishman H.C. (1988).Técnicas de Terapia Familiar. México. Paidós.

DIAZ, S. A. (1996). Educación y violencia familiar. Editorial DYKINSON, S.L.

MONROY, A. (1994). La dualidad del incesto: acto complementario. En Simposium (mayo 1994), De la perversión al amor maduro (55-60) Universidad Intercontinental.

GOICOECHEA, H. P.(n. d). Abuso sexual infantil: manual de formación para profesionales. Save the Children. Obtenida en noviembre de 2001, de http://www.savethechildren.es/ docs/Ficheros/91/Manual.pdf.

FAURA, S. J. F. (n.d). Promoción del buen trato y prevención del maltrato en la infancia en el ámbito de la atención primaria de la salud. Obtenida el 15 de Abril de 2005, en http://www.aepap.org/previnfad/Maltrato.htm.
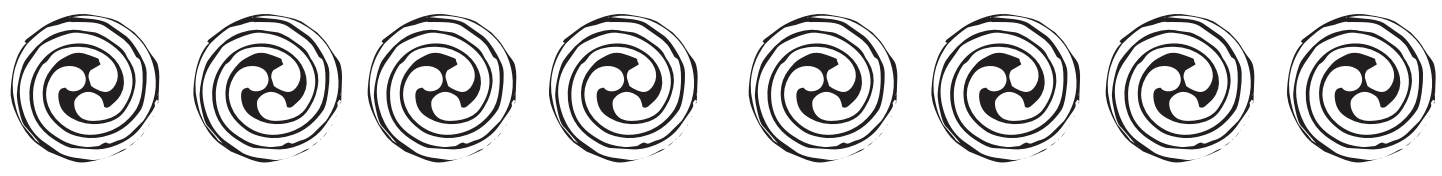


$$
\rho^{\infty}
$$

